\title{
Trends in demand on the organic food market in the European countries
}

\author{
Vasily Nechaev ${ }^{1, *}$, Pavel Mikhailushkin ${ }^{2}$, and Alina Alieva ${ }^{2}$ \\ ${ }^{1}$ Federal Research Center of Agrarian Economy and Social Development of Rural Areas - All \\ Russian Research Institute of Agricultural Economics, 123007, Khoroshevskoye shosse, 35k2, \\ Moscow, Russia \\ ${ }^{2}$ Kuban State Agrarian University named after I.T. Trubilin, 350004, Kalinina str., 13, Krasnodar, \\ Russia
}

\begin{abstract}
The sector of organic agriculture is attractive for investment, and the organic food market demonstrates a dynamic growth. The article suggests methodological approaches to the analysis of demand trends on the organic food market based on the use of growth curves. The dynamics of changes in the consumption of organic products per capita is characterized by a sequential single passage of the stages of development (growth), the achievement of maximum indicators (saturation), recessions, and cessation of existence. As the main factors determining the rate of development and the potential consumption of organic food products per capita, the level of incomes and life of the population was considered. The potential consumption of organic food products per capita in different countries is grounded, taking into account these factors. Based on the analysis of the functions of the growth rates of the per capita demand for organic food products derived from the estimated demand growth curves, the stages of the life cycle of organic food products on the European markets were analyzed, and the exhaustion of the potential demand for organic products in all considered countries except Britain was identified. It is expected that the further expansion of organic food production in the European producer countries will be facilitated by the reorientation to new markets actively importing this product (China, Russia, Japan, and Singapore).
\end{abstract}

\section{Introduction}

Currently, one of the most dynamically growing markets is the global organic food market that is explained by the general development of the organic agriculture sector, the social orientation of the national policies, and the transition to sustainable development of rural areas and resource-saving technologies. There is no universally recognized definition of "organic food" in the world experience, but according to researchers of this category of food and experts from the IFOAM, these are the products derived from organic agriculture. These products lack GMOs, artificial colors, preservatives, flavor enhancers. In the conduct

* Corresponding author: barcho_m@mail.ru 
of organic agriculture, pesticides, herbicides, growth hormones, artificial feed additives, etc. are not used. Certified products have certain logos and markings, which is a guarantee of their high quality and authenticity of the claimed origin, since not only the production passes several stages of thorough testing, but also the farm where it is produced, including soil, ponds, seeds, fertilizers, packaging, and premises. That is why the production of organic products is more labor-intensive and requires increased control and regulation. A characteristic feature of the production of organic food is that much attention is paid to improving the packaging of products, optimizing logistics, and storage and processing technologies [3].

Today, the sector of organic agriculture is attractive for investment. The production processes are the most "transparent" and, therefore, controlled by investors and certification bodies that guarantees the production of high-quality products without adverse environmental impact, and provides a high level of consumer confidence, and, hence, a demand. The greatest prospects for increasing the profitability of agricultural production and, accordingly, the possibility of reducing prices for organic products are associated with the introduction of effective agricultural technologies with low costs and high responsiveness of plants to the means and agro-practices used.

According to the Union of Organic Agriculture, the capacity of market for organic products in Russia is more than 120 million dollars, while only $2 \%$ of agricultural lands (289 thousand hectares) are certified as organic ones according to the international standards [4]. Despite the growing interest of the Russian consumers in organic products, on the domestic market demand continues to outstrip supply, which is currently by $90 \%$ provided by the import producers.

Organic products imported to Russia mainly originate in the European countries, such as Austria, Great Britain, Germany, Italy, Lithuania, France, and Switzerland. In Russia, the imported food products fall into the categories of general consumption (vegetable and fruit preserves, honey, juices, soft drinks, frozen foods, flour, baking ingredients, pasta, tea, coffee, and cocoa), as well as baby food, and dietary and diabetic products. Among the domestic manufacturers of the "organics" which are the main beneficiaries of profit, it is worth noting the large holdings, which managed to establish a full production cycle, including processing products, such as "Black bread", "Ugleche field", "Green farm", "AgriVolga" and others. The difference in the profitability of the certified organic products in comparison with inorganic products reaches $80 \%$. The Russian exporters manage to reach $100 \%$ profitability of sales for individual crops.

In our opinion, the development of markets for organic products is facilitated by the two groups of factors: 1) affecting producers; 2) affecting consumers. Also, we would note that producers of organic products are often their consumers (of different volumes and product categories, including raw materials for further processing and sale). It is natural that in an effort to satisfy the need for crop or livestock of organic products, consumers become producers (usually farmers).

Therefore, to the factors determining the growth of consumer demand for organic food belong the following: health status, healthy lifestyle, environmental care, awareness, income level and state support of consumers, a special worldview in the field of nutrition (for example, vegetarianism and veganism), physical and economic availability of goods, and the development of market infrastructure.

Scientific research in this field, annual analytical reports of international organizations (FAO, IFOAM and Fibl), and initiatives of non-profit organizations play major roles in the development of organic food production that increase the awareness of consumers and producers about "organics".

Among the factors influencing the stimulation of producers of organic products, we distinguish the following: the availability of favorable natural and climatic resources, the 
development of normative and legal regulation, the availability of consulting and certification centers, skilled labor resources, the provision of state support to producers (subsidies, government purchases, tax benefits, etc.), economic and physical access to the resources of production, etc.

In the flagship countries for the organic production, the maturity of the national markets for organic products is determined by the development of its regulatory system - the guarantee system, which includes the following parameters: organic farming standard, certification, certification body, producer certification, producer inspection, and labeling of the finished products [1]. It is the guarantee system that provides quality control of the products, since it allows excluding unscrupulous producers and increasing consumer confidence in this product.

To date, the countries of the European Union, where originally formed the ideas of organic agriculture, possess the most developed guarantee system. Later, they developed in the world production centers, the centers of regulation of production and consumption of organic food. In these countries, their own certification organizations were established, which today influence the development of all global standards in the production of the organic food products.

However, in scientific publications, analytical materials and annual reports of international organizations in this field (Fibl and IFOAM) there are no estimates of the potential market demand for organic food in the main regions of its consumption. The purpose of this study is to refine existing methods for analyzing the development of demand on the agro-food market, identifying factors that determine the potential capacity of the organic food market.

\section{Research methods}

The consumption of organic products per capita in some European countries is considered as a quantitative indicator. The functions of the per capita growth rates of demand for the organic food products, derived from the demand growth curves are analyzed. This allowed identifying the stages of the life cycle of organic food products on the selected European countries markets.

\section{Results}

According to the theory of the product life cycle, it is possible to explain the behavior of new products on the market and to predict their position for future periods on the basis of the correlation-regression analysis model. The dynamics of changes in the per capita consumption of organic food is characterized by a consistent single passage of the following stages: the beginning of existence of an economic object, its development (growth), the achievement of maximum indicators of development (saturation), recession, and cessation of existence. Due to the fact that only the first stages of the life cycle are analyzed, the last two stages are not the objects of our modeling.

The distribution of retail sales volumes (in percentage) by countries of the world and by the European countries is shown on the Figure 1. 

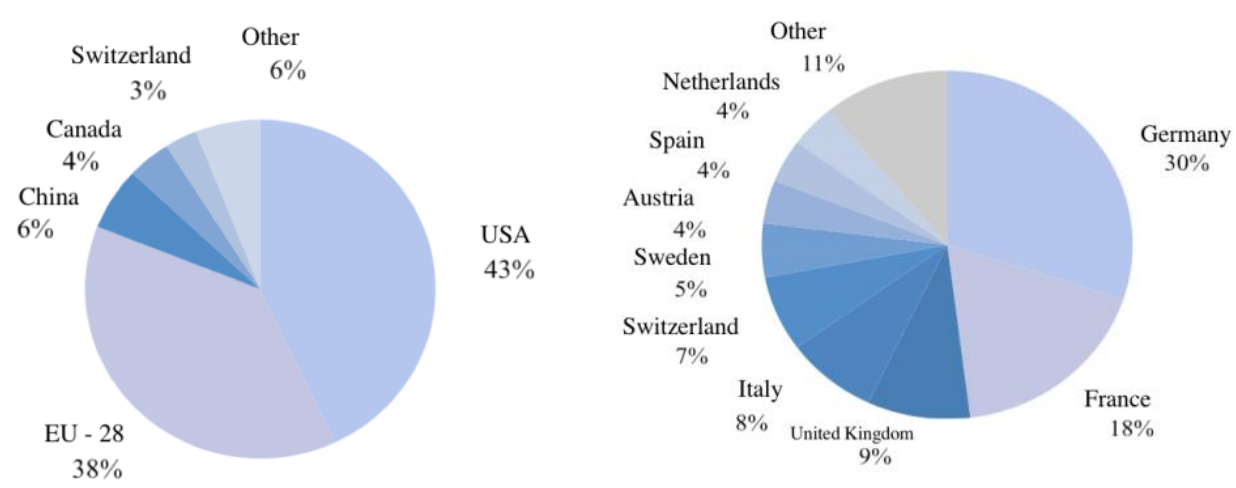

Fig. 1 Volumes of retail sales of the organic agro-food products in the world and in Europe, 2014.

Based on the data presented, it follows that the largest share of the organic food sales falls on such countries as the United States (43\%) and the European Union member states $(38 \%)$. In Europe, Germany, France, and Great Britain are the leaders on this indicator. At the same time, the share of organic products in the overall structure of retail food sales in France is $2.6 \%$, in Germany $-3.7 \%$, in Sweden - $4.3 \%$, in Austria - 6.5\%, in Switzerland $7 \%$, and in Denmark - $8 \%$.

The growing interest in the new category of consumer demand (organic products) influences the growth in supplying these products among producers. However, such parameters as the growth in demand in a wider range of consumers and in new consumer segments, and the response of the market supply of goods to this demand is determined by time, financial resources and mentality of the population of different countries.

When a new segment in the structure of the food market is being formed, only a small "advanced" part of the population is interested in this qualitatively new product. However, representatives of effective demand, marketing activity and time contribute to an increase in the volume of the market, the growth of which acquires an "explosive" character, when the rate of change of the indicator is proportional to its current value. Exponential development based on the assumption of a constant rate of change in function is characteristic only for the stage of growth of the life cycle of the product market [3]. The exponential curve can be expressed as follows:

$$
\frac{d y}{d t}=k y \text {. }
$$

Integrating both parts of equality (1), we will obtain:

$$
\ln y=k t+C,
$$

where $y$ is the final consumption of the goods in the country,

$C$ is an arbitrary constant.

Let us imagine it in the form: $C=\ln y_{0}$, where $y_{0}$ is the initial state of the process, $\mathrm{k}$ is the growth rate of the indicator.

Exponentiating the equality (2), we will obtain:

$$
y=y_{0} e^{k t}
$$

But the acceleration of growth in consumption of products cannot be a constant in the long term, and as the coverage of all potential consumers increases, the growth will decline. 
It will stop when the number of active users approaches the total number of potential consumers, and the per capita consumption limit will be formed based on the achieved level of disposable per capita income. The differential equation of the process near the saturation level $L$ takes the form:

$$
\frac{d y}{d t}=k(L-y)
$$

Changing variables $z=L-y$ we will have the equation: $\frac{d z}{d t}=-k z$. Thus $z=z_{0} e^{-k t}$, then:

$$
L-y(t)=z_{0} e^{-k t}
$$

Let us write the general equation for: $\frac{d y}{d t}$, the solution of which for small values of $y$ is close to $y=y_{0} e^{k t}$, and for large values (close to $\left.L\right)-L-y(t)=z_{0} e^{-k t}$ :

$$
\frac{d y}{d t}=k y(L-y)
$$

The dependence of the form (6) is a logistic function:

$$
y=\frac{L}{1+a \cdot e^{-k t}} .
$$

The logistic function (7) takes the form of an increasing exponent for small values of the variable $y$ and "decays" for large values.

Quantitative assessment of the change in the growth rate of demand for organic food on the markets of the European countries is of great interest for this work. To do so, we will express the growth rate from (7) as:

$$
\frac{Y_{t}}{Y_{t-1}}=\frac{L-Y_{t}}{L-Y_{t-1}} e^{k\left(t_{1}-t_{2}\right)}
$$

It can be seen from (8) that for initial values of $Y t$, which are far from the saturation limit $L$, the ratio in the right-hand side of the equation will be approximately equal to 1 , then the rate of growth of the indicator will be described by exponential development with a parameter $k$.

In the case when $t$ is introduced into the equations (7) to a high degree, the exponential growth rate will increase. At finite levels of the series $Y t$, close to $L$, the left side of the equation will be equal to 1 . Then, the growth rate will be formed by the exponential decay of the difference with the parameter $k$ :

$$
e^{-k\left(t_{1}-t_{2}\right)}=\frac{L-Y_{t}}{L-Y_{t-1}}
$$

As it was noted earlier, the income level of the population is one of the main factors determining the speed of development and the potential volume of the market of organic 
food products. Average consumption of organic products in the world ranges from 2-3 euro / person (Russia, Latvia, Hungary, and China) to 160-221 euros / person (Denmark, Luxembourg, and Switzerland). According to the data of Fibl Institute, Switzerland, Denmark, Austria, Sweden, USA, Germany, and France are the countries with the largest expenditure on consumption of organic products.

In the framework of this study, the following regularity was established: with an increase in per capita income per $1 \%$, per capita consumption of organic products throughout the year in the European countries increases by an average of 3.95\% (Figure 2).

According to the Figure 2, the European countries, similar in their level of overall socioeconomic development, have a similar level of development of the organic food markets. Analyzing the income level of the population and a fairly stable social structure in Europe, it is possible to justify the potential capacity of organic food markets in the main European consumer countries of organic products.

Analyzing the statistical indicators of consumption of the organic food products per capita for the period from 1997 to 2015 in the European countries, we have simulated the life-cycle curves of these products.

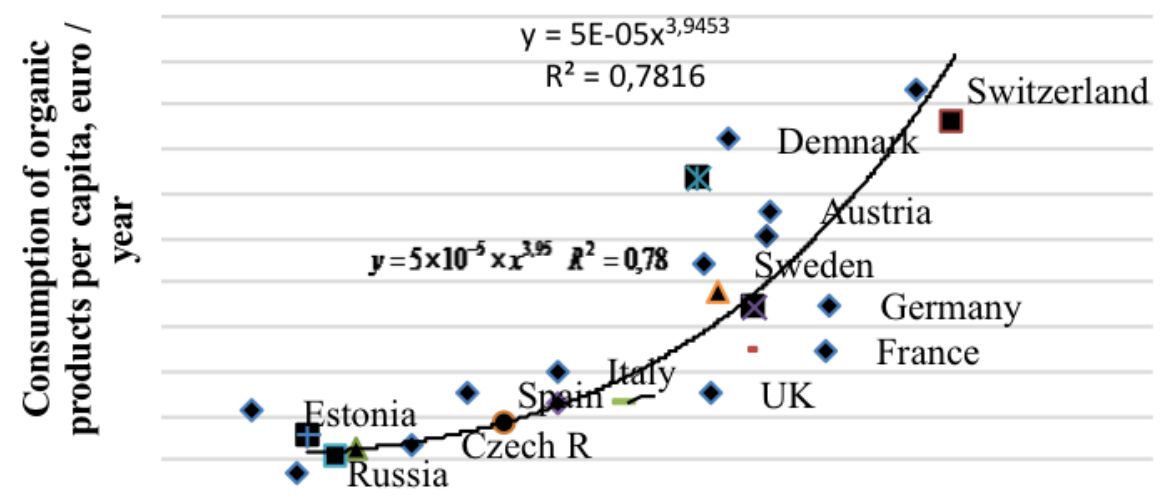

Average per capita income, euro / day

Fig. 2. Dependence of consumption of organic products on the average per capita income in different countries.

Thus, in 2015, the highest level of consumption of organic food products per capita $(Y)$ was reached in Switzerland, which amounted to 262 euros per year. Assuming that the limit of "saturation" is 300 euros, the following dependence was obtained:

$$
\mathrm{Y}_{\text {Switzerland }}=\frac{300}{1+3,303 \mathrm{e}^{-2,475 \cdot 10^{-5} \cdot \mathrm{t}^{4}}}, \mathrm{R}^{2}=88,8 \%, \mathrm{~F}=135,2, \mathrm{n}=19 .
$$

The need to introduce in the equation the serial number of the year in the high fourth degree shows the "explosive" development of demand for the products in Switzerland at the time of formation of the analyzed market.

The next group of countries, similar in terms of socio-economic development, includes Austria, Germany and France. In Austria, from 2012 to 2015, the level of consumption remains at the level of 126 euros per capita, which allows us to admit the demand saturation limit of 130 euros. Then the estimated logistic curve of the final per capita demand for organic products in Austria will take the form:

$$
\mathrm{Y}_{\text {Austria }}=\frac{130}{1+2,069 \mathrm{e}^{-0,014 \cdot \mathrm{t}^{2}}}, \mathrm{R}^{2}=93,2 \%, \mathrm{~F}=192,14, \mathrm{n}=16
$$


Despite the fact that the level of per capita consumption of organic products in Germany is lower than in Austria (106 euros against 126), the active process of increasing the final demand of the population for organic products is still ongoing. The logistic curve of the ultimate per capita demand for organic products in Germany looks like that:

$$
\mathrm{Y}_{\text {Germany }}=130 \mathrm{e}^{-1,691 \mathrm{e}^{-0,006 \mathrm{t}^{2}}}, \mathrm{R}^{2}=98,1 \%, \mathrm{~F}=741, \mathrm{n}=16 .
$$

In France, the process of forming the market for organic products is slowing down, and the level of the reached per capita consumption of this product is lower than in the analyzed countries. Thus, the trend of the formation of per capita demand for organic products in this country was modeled in the following curve:

$$
\mathrm{Y}_{\text {France }}=100 e^{1,703 e^{-1,822 \cdot 10^{-5} \cdot t^{4}}} \mathrm{R}^{2}=92 \%, \mathrm{~F}=197,5, \mathrm{n}=19 .
$$

Given the almost identical living conditions of the population in Denmark and Sweden, in these countries the limits of saturation of the per capita demand for these products were adopted equal to the amount of consumption in Denmark - 200 euros. The obtained logistic curves of the per capita consumption of the "organics" have the form:

$$
\begin{aligned}
\mathrm{Y}_{\text {Denmark }} & =\frac{200}{1+1,897 \mathrm{e}^{-2,779 \cdot 10^{-5} \cdot \mathrm{t}^{4}}}, \mathrm{R}^{2}=85,4 \%, \mathrm{~F}=87,5, \mathrm{n}=17, \\
\mathrm{Y}_{\text {Sweden }} & =\frac{200}{1+3,491 \mathrm{e}^{-0,023 \cdot \mathrm{t}^{2}}}, \mathrm{R}^{2}=92,5 \%, \mathrm{~F}=109,8, \mathrm{n}=11 .
\end{aligned}
$$

The next group of countries to be analyzed includes Italy, Spain and the United Kingdom. In 2015, the level of the per capita consumption of organic products in Italy was 38 euros and in Spain - 32 euros. In Spain, the growth in demand for organic products took a more "explosive" character than in Italy, which is expressed in a high degree of the ordinal number of the year in the equation of the curve:

$$
\begin{gathered}
\mathrm{Y}_{\text {Italy }}=\frac{45}{1+1,571 \mathrm{e}^{-0,006 \mathrm{t}^{2}}}, \mathrm{R}^{2}=74,3 \%, \mathrm{~F}=49,2, \mathrm{n}=19, \\
\mathrm{Y}_{\text {Spain }}=\frac{40}{1+3,704 \mathrm{e}^{-1,878 \cdot 10^{-5} \cdot \mathrm{t}^{4}}}, \mathrm{R}^{2}=80,5 \%, \mathrm{~F}=37,3, \mathrm{n}=11 .
\end{gathered}
$$

Demand for the organic food products among the population of Great Britain is increasing. However, in the considered time period of this indicator, three stages can be traced: 1) a growth before the financial crisis of 2007; 2) a four-year reduction in the per capita consumption; 3) from 2011 to 2015, a further increase in consumption. According to the analytical data of Fibl and IFOAM, in 2017, after the prolonged stagnation, a small growth of this market was registered [2].

In modeling of the time series trends, the nature of which was affected by general structural changes, it is possible to use Damodar Gujarati statistical testing method, in which linear regression equation with dummy variables has the following form:

$$
y=a+b \cdot z_{t}+c \cdot t+d \cdot\left(z_{t} \cdot t\right)+\varepsilon_{t}
$$

where $y$ is the dependent variable;

$t$ is the serial number of the year;

$\mathrm{a}, \mathrm{b}, \mathrm{c}, \mathrm{d}$ are estimated regression parameters;

$\varepsilon_{t}$ is a regression error; 
$z_{t}$ is a dummy variable that is equal to zero if $t>t^{*}$, and is equal to 1 , if $t<t^{*} ; t^{*}$ is the moment of time, accompanied by significant changes in environmental factors.

The equation that explains the per capita demand for organic products in the UK is:

$$
\begin{gathered}
\mathrm{Y}_{\text {Britain }}=11,88+0,29 t^{2}+45,7 z_{1}-45,01 z_{2}-0,43 z_{1} t^{2}+0,21 z_{2} t^{2}, \\
\mathrm{R}^{2}=95,3 \%, \mathrm{~F}=52,5, \mathrm{n}=19,
\end{gathered}
$$

where $t=1,2, \ldots, 19$ - the serial number of the year from 1997 to 2015;

$z_{1}$ is a dummy variable, the value of which is zero for the period 1997-2007, and 1 - for subsequent years.

$z_{2}$ is a dummy variable that takes values equal to zero for 1997-2011, and 1 for the subsequent years.

So, for the first period we get the following equation:

$$
y=11,88+0,29 t^{2} .
$$

The equation that characterizes the dynamics of per capita demand for organic products in the UK from 1998 to 2011 is as follows:

$$
\begin{gathered}
\mathrm{Y}_{\text {Britain }}=(11,88+45,7)+(0,29-0,43) t^{2} \\
\mathrm{Y}_{\text {Britain }}=57,58-0,14 t^{2} .
\end{gathered}
$$

During the last four years of the analyzed period, the growth rate of the per capita consumption of this product was $7 \%$ per year:

$$
\mathrm{Y}_{\text {Britain }}=12,57+0,07 t^{2}
$$

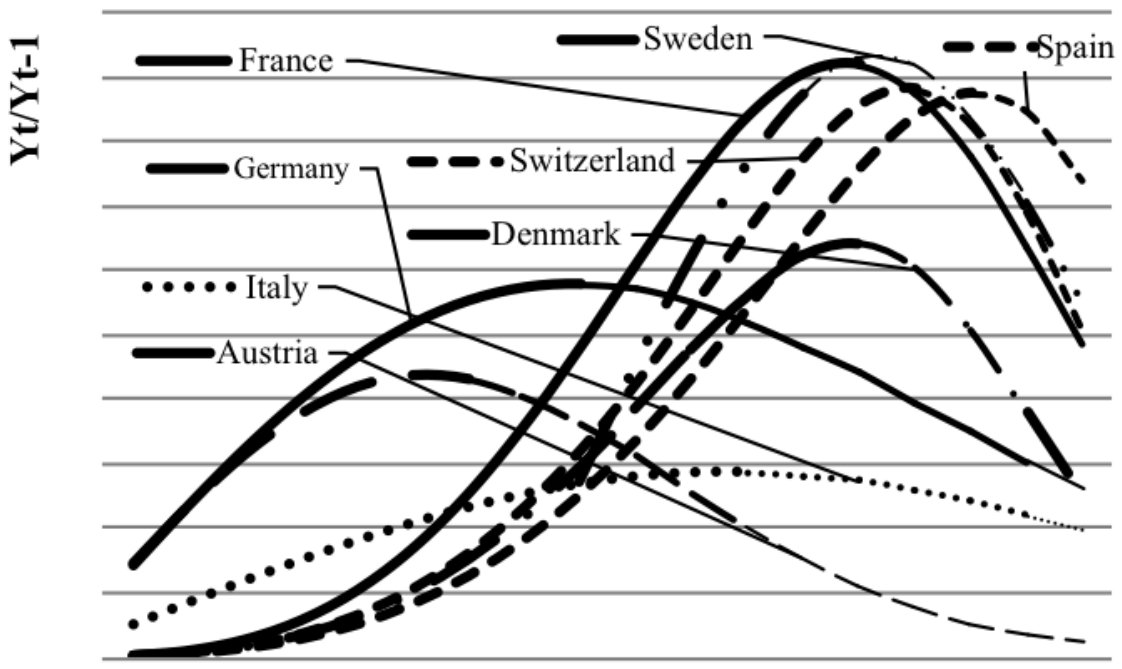

Fig. 3. Functions of the growth rates of demand for organic products per capita in the European countries.

The change in the growth rate of per capita consumption of organic food products in the European countries $Y t / Y t-1$ in the analyzed period, estimated according to (8) and based on the received logistic curves, is shown on the Figure 3. 
Let us conventionally assume that the period, at which the growth of per capita consumption increases exponentially, will be a period of the "explosive" growth in per capita demand for the organic food products. The period, in which the growth rate of the indicator is reduced relative to the period of the "explosive" growth, will be the period of slowing growth in demand. The period, in which the growth rate is less than $4 \%$, will mean the saturation of demand.

\section{Discussion}

In Switzerland, per capita demand for organic products increased at an "explosive" rate until 2008. Since 2009, the growth rate has been decreasing, and in 2015 the growth rate was $10 \%$. Based on the data obtained, it can be concluded that the growth of the organic food market can be provided by lower prices, additional marketing activities or an increase in the population of the country, the pace of which is not high. In addition, the stagnation of demand will encourage producers to search for new resource-saving technologies and, possibly, the emergence of new products on this market (for example, products of new varieties or species, processed products, etc.).

Among the countries analyzed, Austria has the most "mature" demand for organic food. Until 2003, the "explosive" demand for organic food was observed, and since 2009 - the saturation of the market happened. Similarly, the potential capacity of the Danish market has been exhausted. In Sweden, the growth of demand was not so dynamic; therefore, the phase of its saturation has not yet come.

In Germany, throughout the analyzed period, one can observe a slowing growth in per capita demand, which was about $6 \%$ in recent years. The average growth rate of per capita demand in France from 2006 to 2011 reached 15\%, but now the rate is decreasing, aiming for saturation.

Similar to Germany, the dependence of demand for organic food is observed in Italy, where since 2009 has been a slow decline in the demand growth rates. In Spain, for this period, there is an end of the "explosive" growth with a gradual decline.

With the exception of Great Britain, in all analyzed European countries there is an exhaustion of potential demand for the organic food products. However, it does not exclude the possibility of further growth.

\section{Conclusion}

In foreign countries, the effective functioning and dynamic development of the organic food markets largely depends on the elaboration and development of institutional and legal factors. The demand is determined by the general state of the market (the volume of the assortment, the availability of diversified sales channels and the regulation), the level of economic development of the country, the existing culture of nutrition, and the technological development of organic production, which all together affect the quality of products and the customers' loyalty. At the same time, not the least role is played by the social orientation of the state policy of the European countries (the orientation towards raising the level and quality of life of the population), the activities of public organizations, the popularization of ideas for a healthy lifestyle, and the attention to the environmental problems.

Nevertheless, the growing economic and political instability in the European countries (migration problems, the exit of the UK from the EU, the referendum in Catalonia, etc.) contribute to the instability of exchange rates, the overall decline in the growth of consumer markets, including the organic food markets. Together, these trends contribute to the 
changing orientation of producers of the "organics" to new markets, actively importing this product.

So, the consumption of the organic food products in China is rapidly growing: in 2016, the market growth rate was $45 \%$ by 2015 , and the total area of the certified agricultural land for organic farming increased by $40 \%$ - from 1.7 million hectares to 2.2 million hectares for the same period. Also, in China a special certificating body has been created with the purpose of development of own manufacture of organic production, and the national "organic" marking has been introduced.

In addition, according to the forecasts of the experts of the Union of Organic Farming, Russia has great prospects on the global market of organic products, since the area of the certified agricultural land has increased by more than 5.5 times only in the last 5 years (from 2013 to 2018), and the number of the certified manufacturers increased from 40 in 2007 to 55 in 2018.

At present, the "organic" direction is one of the priorities on the agenda of the governments of China, Russia and the CIS countries, and active development of regulatory and legal standards and measures of state support of producers is being carried out. Therefore, experts' forecasts related to the implementation of Russia and China potentials on the global market of organic products have good prospects to become a reality in the long term.

However, to date, domestic demand for the "organics" in China, in Russia, and in other Asian countries (Singapore, Japan, South Korea, and Taiwan) is still satisfied by imports from the European countries, and in the short run (2-3 years) there are no prospects for changes.

\section{References}

1. A. I. Altukhov, V. I. Nechaev, B. N. Porfiryev, Zh. E. Sokolova, P. V. Mikhailushkin, V. V. Taran, «Green» agricultural economics (RSAU-MSAA, Moscow, 2014)

2. Research Institute of Organic agriculture (FiBL), Official website (http://www.fibl.org/)

3. H. Willer, J. Lernoud, The world of organic agriculture: sstatistics and emerging trends (Research Institute of Organic Agriculture (FiBL), Frick, IFOAM-Organics International, Bonn, 2018

4. Union of Organic Farming, Official website (www.sozrf.ru) 